\title{
The Role of Th17 Cells and IL-17 in Th2 Immune Responses of Allergic Conjunctivitis
}

\author{
Xiang-Tian Meng, ${ }^{1}$ Yun-Yue Shi, ${ }^{2}$ Hong Zhang $\mathbb{D}^{1},{ }^{1}$ and Hong-Yan Zhou ${ }^{1}{ }^{1}$ \\ ${ }^{1}$ Department of Ophthalmology, China-Japan Union Hospital of Jilin University, Changchun 130033, Jilin Province, China \\ ${ }^{2}$ Department of Obstetrics and Gynecology, China-Japan Union Hospital of Jilin University, Changchun 130033, \\ Jilin Province, China
}

Correspondence should be addressed to Hong-Yan Zhou; zhouhongyan7301@sina.com

Received 20 February 2020; Accepted 12 May 2020; Published 25 May 2020

Academic Editor: Alessandro Meduri

Copyright (c) 2020 Xiang-Tian Meng et al. This is an open access article distributed under the Creative Commons Attribution License, which permits unrestricted use, distribution, and reproduction in any medium, provided the original work is properly cited.

\begin{abstract}
Allergic conjunctivitis (AC) is a common allergic disease that is often associated with the onset of rhinitis or asthma. The incidence of AC has increased significantly in recent years possibly due to air pollution and climate warming. AC seriously affects patients' quality of life and work efficiency. Th (T-helper) 2 immune responses and type I hypersensitivity reactions are generally considered the basis of occurrence of AC. It has been found that new subpopulations of T-helper cells, Th17 cells that produce interleukin-17 (IL-17), play an important role in the Th2-mediated pathogenesis of conjunctivitis. Studies have shown that Th17 cells are involved in a variety of immune inflammation, including psoriasis, rheumatoid arthritis, inflammatory bowel disease, systemic lupus erythematosus, and asthma. However, the role of Th17 and IL-17 in AC is unclear. This paper will focus on how T-helper 17 cells and interleukin-17 are activated in the Th2 immune response of allergic conjunctivitis and how they promote the Th2 immune response of AC.
\end{abstract}

\section{Introduction}

Allergic conjunctivitis (AC) is an inflammatory disorder of conjunctivae which negatively affects the family and daily activities and is responsible for significant work and school absenteeism [1,2]. The prevalence can vary in intensity, seasonality, gender, country, and region [3-6]. However, the consensus is that a number of researchers have reported that the incidence of allergic diseases, including various types of allergic conjunctivitis, has increased significantly [7-10]. This discrepancy could be attributed to indoor and outdoor air pollution and the increased pollen due to climate change and global warming [11-14]. Several reports have shown that AC is closely related to asthma, rhinitis, and other allergic diseases, which seriously affects the quality of life of patients and productivity [5-7, 15-17]. In addition, the incidence of $\mathrm{AC}$ is related to many factors. The prevalence of allergic rhinitis, allergic conjunctivitis, and asthma has significantly increased among the general population, especially in developed cities with severe air pollution. This phenomenon supports the link between industrialization and allergic diseases [18]. Gabet et al. demonstrated that children who are highly sensitive to dust mites have the highest risk of developing allergic diseases [19]. The condition is often classified as seasonal allergic conjunctivitis (SAC), perennial allergic conjunctivitis (PAC), atopic keratoconjunctivitis (AKC), vernal keratoconjunctivitis (VKC), and giant papillary conjunctivitis (GPC) $[1,20,21]$. Th2 immune responses and type I hypersensitivity reactions are generally considered the basis of occurrence of AC [22]. An European Academy of Allergy and Clinical Immunology (EAACI) task force suggested to include "ocular allergy" in the "ocular surface hypersensitivity disorders," dividing the different forms into IgE-mediated and non-IgE-mediated diseases [20, 23]. SAC and PAC are typical IgE-mediated allergic reactions. AKC and VKC include both IgE-mediated immunity and non-IgE-mediated immunity. GPC is a disease related to contact lenses wear, which is not considered 
any longer as an allergic disorder but still included within the allergic conjunctivitis. SAC and PAC do not have discernible difference in the symptoms such as ocular itching, hyperaemia, dry eye, redness, and lid swelling, and also, tearing, mucous discharge, and burning may occur [20, 24-26]. They all belong to the acute type of allergic conjunctivitis. However, SAC, due to airborne pollen allergens, usually occurs during allergy season in spring and summer [10, 27]. Patients sensitized to perennial allergens instead, like insects, household molds, house dust mites, or animal epithelia, can suffer from PAC and experience symptoms throughout the year $[10,20,27]$. So, the key differentiator between SAC and $\mathrm{PAC}$ is their occurrence time and duration of discomfort. Therefore, some scholars believe that SAC and PAC are actually the same disease manifested in different forms [28]. Since SAC and PAC as well as intermittent and persistent rhinitis often occur together, while eye or nasal symptoms alone are rare, they are grouped together as allergic rhinoconjunctivitis $[2,29]$. In temperate zones, the SAC percentage is 90 percent, and the PAC percentage is 5 percent; however, in tropical climates, PAC seems to be more common $[8,16]$. So, they have a significant impact on the quality of patient's life and affect social economy [30]. Although VKC and AKC account for only $2 \%$ of ocular allergy cases, they have a greater impact on life [22]. Unlike SAC and PAC, VKC and AKC appear as corneal involvement. So, $\mathrm{AKC}$ and $\mathrm{VKC}$ are sight-threatening keratoconjunctivitis $[8,31]$. Infiltration and activation of eosinophils are the main causes of corneal complications in chronic allergic diseases [32]. It has been found that new subpopulations of T-helper (Th) cells, Th17 cells that produce interleukin-17 (IL-17), play an important role in the Th2-mediated pathogenesis of conjunctivitis. Studies have shown that Th-17 cells are involved in a variety of immune inflammation, including psoriasis, rheumatoid arthritis, inflammatory bowel disease, systemic lupus erythematosus, and asthma [33, 34]. However, the role of Th17 and IL-17 in AC is unclear. Therefore, this article will focus on the activation and action of Th17 cells in the Th2-type immune responses to introduce the immunological mechanism of AC and the new progress in diagnosis and treatment.

\section{Classical Biological Mechanisms}

Conjunctiva is one of the most common sites of allergic inflammation due to direct exposure of the conjunctiva and easy contact with allergens. In the sensitization phase, the initial genetic susceptibility of individual ocular exposure to a novel allergen, which is processed and presented by dendritic cells (DC) and/or other antigen-presenting cells (APC), causes naive CD4 cells or helper T cells (Th0) to mature and differentiate into Th2 lymphocytes [35]. Sensitization and differentiation of Th2 cells require antigen presentation by DC [35]. Th2 cells mainly participate in IgEmediated allergies through the release of IL-3, IL-4, IL-5, IL9, IL-10, and IL-13. These allergies include B cells producing IgE, mast cell growth, and aggregation of acid granulocytes [32]. When the antigen peptide-MHC molecule located on the surface of B cells interacts with the TCR located on the surface of CD4 cells, B cells proliferate and differentiate into plasma cells, secrete antigen-specific IgE, and aggregate the high-affinity IgE receptor (FceRI) located on the surface of mast cells (MC) and basophils [32]. Th2-derived cytokines, such as IL-4 and IL-5, are involved in eosinophil activation and chemotaxis $[36,37]$. When the same allergen is encountered as the eye was previously allergic, the allergen attaches to the IgE-FceRI complex and cross-links to the mast cell surface. MCs express FceRI, IgE-FceRI complex, and allergen-based epitope cross-link to activate mast cells to release their preformed mediators such as histamine, proteolytic enzymes, and proteoglycans as part of the early response and then the reaction part as a late rapid synthesis of leukotrienes and prostaglandin lipid mediators [38]. IgEFceRI cross-linking generates a signal that lyses mast cell membrane phospholipids, releasing them, and produces a wide range of MC-derived mediators, including IL-2, IL-3, IL-4, IL-5, IL-6, IL-10, IL-12, granulocyte-macrophage colony-stimulating factor (GM-CSF), and TNF- $\alpha[39,40]$. Among them, IL-3 and IL-5 are involved in the development, survival, and recruitment of eosinophils, which are helpful for the occurrence of eosinophilic inflammation. Histamine is the main agent involved in ocular anaphylaxis [41]. Among the known histamine receptors, H1R, H2R, and $\mathrm{H} 4 \mathrm{R}$ subtypes are closely related to eye allergies. Histamine signals have been shown to increase conjunctival hyperemia, fibroblast proliferation, cytokine secretion, expression of adhesion molecules, microvascular permeability, and procollagen production through $\mathrm{H} 1 \mathrm{R}$ and $\mathrm{H} 2 \mathrm{R}$ [41]. H4R regulates a variety of physiological functions, including the release of cytokines and chemokines, expression of adhesion molecules and chemotaxis, and recruitment of mast cells, eosinophils, dendritic cells, and lymphocytes into the conjunctiva $[42,43]$. Then, in late-phase response, activated eosinophils result in the release of inflammatory cytokines including eosinophil cationic protein (ECP), eosinophil peroxidase, neutrophil toxic oxygen free radicals, proteases, and Th2 lymphocytes, among others, some such as major basic proteins (MBP) and ECP are toxic to the corneal epithelium [44, 45] (Figure 1).

\section{Th17 and IL-17 in AC}

3.1. Th17 and IL-7 May Promote AC. Th17 is a T-cell lineage different from Th1 and Th2 cells and is considered to be a novel preinflammatory $\mathrm{T}$ effector cell [46]. In 2005, researchers found so-called helper T cells, "Th17 subsets," in mice as a $\mathrm{T}$ helper subset distinct from Th1 and Th2 cells [47]. It is mainly in the regulation of immune responses and clearance of extracellular pathogens that TH17 cells play a role [48]. Retinoid-related orphan receptor $\gamma \mathrm{t}(\mathrm{ROR} \gamma \mathrm{t})$ is needed in Th17 cell differentiation [49]. IL-17A (also called IL-17) is the signature cytokine of Th17 cells [48], but they also produce IL-17F, IL-22, and GM-CSF [50-52]. Among them, IL-17A also is the most widely distributed [53]. Although IL-17 is most richly expressed by Th17 cells, it can also be produced by other immune cells, including macrophages, B cells, natural killer T cells, innate lymphocytes, and CD8+T cells [54]. Indeed, IL-17 and Th17 cells have 


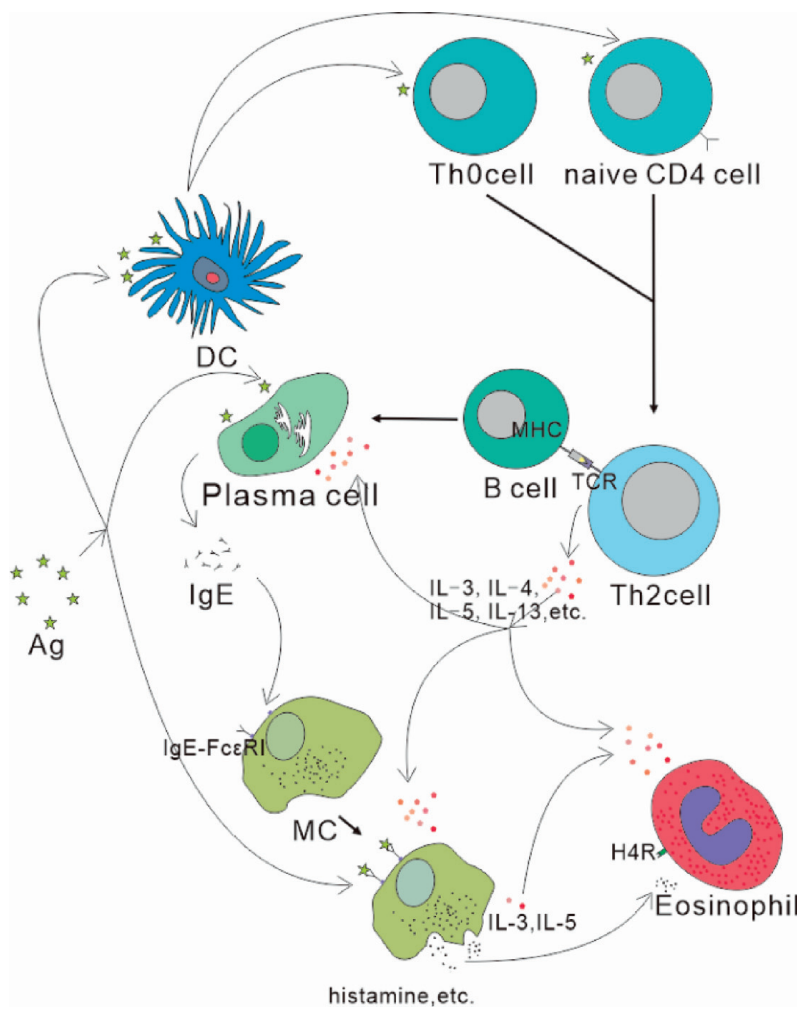

FIGURE 1: In classical type I hypersensitivity reactions, activation of individual cells and immune molecules finally results in mast cell degranulation and eosinophil infiltration. Factors such as IL-3, IL4, IL-5, and IL-13 produced by Th2 cells promote this process.

been shown to be associated with human autoimmune diseases in many tissue regions, including psoriasis, rheumatoid arthritis, inflammatory bowel disease, systemic lupus erythematosus, and asthma [55-61]. Recent evidence suggests that Th17 cells are also associated with Th2 hypersensitivity $[62,63]$. Extensive data indicate that Th17 cells and IL-17 have proinflammatory roles in allergic airway disease [64]. The concentrations of IL-17A, IL-17F, and IL22 in bronchoalveolar lavage fluid and bronchi in asthmatic patients are positively correlated with disease severity and airway responsiveness $[65,66]$. This further aggravates the allergic reaction [67]. IL-17-deficient mice reduced airway inflammation after Ag attack [68], and neutralization of IL17 reduced Th2-induced allergic airway disease [55, 69, 70]. Recently, it reported that ROR $\gamma$ t and IL-17 levels were elevated in nasal lavage fluid in allergic rhinitis mice [71]. Kinyanjui et al.'s data also show that low doses of IL-17 can enhance Th2-dependent airway inflammation [64]. Castaneda et al.'s experiments also support the hypothesis that air pollution exacerbates the allergic immune response by enhancing the Th17 immune response [72]. Currently, Th17 cells or IL-17 have also been found in inflammatory diseases of the eye such as uveitis, scleritis, diabetic retinopathy, and dry eye [73-77]. All these suggest that both Th17 cells and IL-17 may participate in and deepen the Th2 response in AC [73]. The role of Th17 cells in allergic conjunctivitis is a relatively new concept. However, the role of Th17 in AC is largely unknown. In a recent experiment, the significant stimulation and activation of Th17 cytokines, IL-17A and IL$17 \mathrm{~F}$, and the specific transcription factor ROR $\gamma \mathrm{t}$ in a mouse model of allergic conjunctivitis showed when developmental enhancement can aggravate Th2-dominant allergic inflammation in allergic eye disease [78].

3.2. Activation of Th17 Cells. Activation state of DC is essential to Th2 cells and Th17 cells $[79,80]$. DC are "important APC" and play an important role in presenting antigens and inducing primary immune responses. Kudo M et al.'s studies suggest that Th17 cell differentiation may be associated with avb8 integrin on DCs [81]. CD40 and CD86 signaling appears to be critical in the induction of Th17 cells [82]. In the meantime, because differentiated $\mathrm{TH}$ cells have plasticity, Th2 cells can be differentiated into Th2/Th17 cells [83]. This means that, in eye allergies, activated Th2 cells can be directly transformed into Th17 cells. Meanwhile, when natural T cells are activated under the action of transforming growth factor $\beta$ (TGF- $\beta$ ) and IL- 6 and IL-23 secreted by APC, signal transduction and activation of transcription factor 3 (STAT3) and RORC2 are activated to differentiate into Th17 cells $[82,84]$. And then, IL-23 will support the maintenance of Th17 cell function [85]. Furthermore, expression of IL-17A has been reported to be related to eosinophils which produced IL- 6 and TGF- $\beta[48,53,86]$. So, DC and eosinophils activated in AC may support Th17 differentiation $[62,65,79]$ (Figure 2).

3.3. Role of IL-17 in Th2 Immune Responses. IL-17 is a wellknown proinflammatory property. IL-17 plays an important role in maintaining health in response to injury, physiological stress, and infection [60]. The exact role of IL-17 in $\mathrm{AC}$ is unclear. Interestingly, it proved to be not only a positive role in regulating the immune response but also a negative regulatory role as well [87]. Some studies have shown that Th17 cell development is enhanced, which exacerbates the dominance of Th2 [73]. Due to the plasticity of differentiated $\mathrm{T}$ helper cells, under the stimulation of IL-4, Th17 cells can be transformed into IL-2 producing Th2 cells [85]. Adoptive transfer of Th17 cells and Th2 cells can promote antigen-induced Th2-mediated eosinophil inflammation [63]. T cells that produce IL-17 induce neutrophilia in mice, and these cells also actively regulate Th2driven eosinophilia [64]. Studies have found that the Th2 response is weakened in the absence of IL-17R signals due to impaired Th2 cell activation, and mouse models lacking the IL-17R gene show airway eosinophil recruitment, and eosinophil peroxidation activity was reduced [88]. Some scholars have confirmed that IL-17A and IL-17F can promote the production of eosinophils CXCL1, IL-8, and CCL4, as well as IL- $1 \beta$ and IL- $6[74,78]$. This may be related to the fact that the IL-17 signal promotes the interactions required to promote germinal center (GC) formation of CD4+T cells and B cells [89]. Meanwhile, the GC-B cell development and humoral responses of the mouse lacking the IL-17 receptor were reduced, which suggests a mechanism through which IL-17 drives the autoimmune response by promoting the formation of spontaneous GCs [89]. In addition to these, 


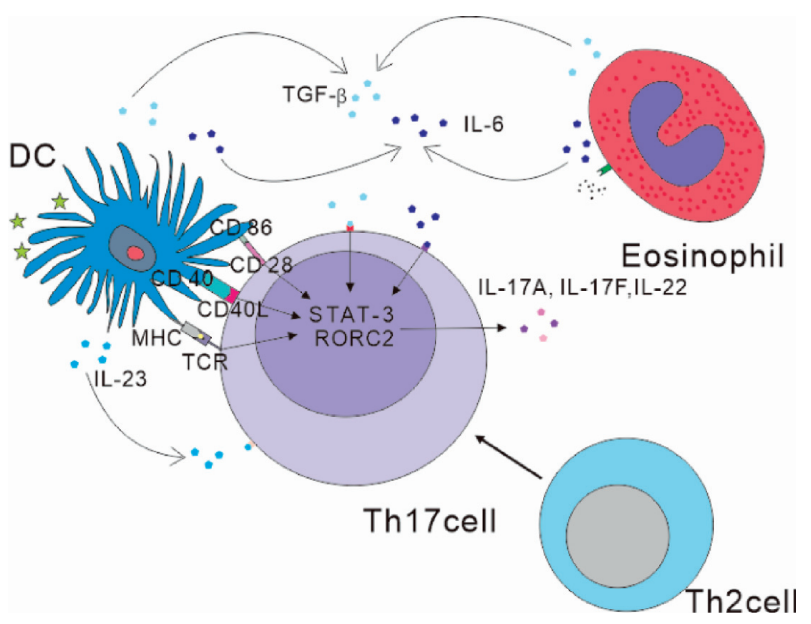

Figure 2: 1. CD40 and CD86 signaling on DC appears to be critical in the induction of Th17 cells. 2. IL-23 supports the maintenance of Th17 cell function. 3. IL- 6 and TGF- $\beta$ produced by eosinophil and DC expression promote Th17 cell differentiation. 4. Activated Th2 cells can be directly transformed into Th17 cells.

Th17 cells have been shown to help B cell differentiation and to play a key role in the formation of ectopic lymphoid follicles in the target organ [89]. Other researchers also demonstrated Th17 cells as helper B cells because they not only help in in vitro proliferation of B cells to produce a strong reaction but also class switch recombination in vivo by triggering the production of antibodies [90]. Eosinophils are derived from progenitor cells in the bone marrow and can be differentiated by IL-3, IL-5, and GM-CSF [51]. And the prominent role of eosinophils in chronic colitis has been confirmed as GM-CSF regulation from Th17 cells [91]. GMCSF secreted by Th17 cells maintains the eosinophilic mucosa and enables the activation of eosinophils [92]. In addition, previous studies found IL-23-Th17 cells feedback loop, wherein IL-23 maintained Th17 cell population, produced IL-17, and also induced Th17 cells to secrete GMCSF, and GM-CSF in turn induced antigen-presenting cells to further secrete IL-23, thereby constantly maintaining the Th17 cell chronic reaction [93]. This means that, in eye allergies, Th17 may also aggravate the symptoms by this route. Therefore, IL-17 can promote the aggregation of IgE and eosinophils. This also further promotes the maintenance of the immune response. A 2017 study showed that IL-17A was involved in the pathophysiology of allergies by increasing the ability of IL-13 to activate signaling pathways such as intracellular signal transduction and activation of transcription factor 6 (STAT-6). This is the first mechanistic explanation of how IL-17A directly enhances Th2 response [91]. Study finds that IL-17 from T cells has a dose-dependent effect on IL-13-induced allergic airway inflammation [92]. So, higher doses of IL-17 can attenuate the inflammatory response induced by IL-13. There are also reports showing that increased IL-17A protein expression synergizes with IL-13 [68]. Laboratory has demonstrated that when IL-22 gene-knockout mice received induced airway eosinophils, IL-13 expression was reduced [62]. However, neutralization of IL-22 with an antibody increased
IL-13 protein expression [94]. This means that IL-22 may have a dual role in allergies (Figure 3 ).

\subsection{The Effects of Other Signaling Molecules on Th17 Cells}

3.4.1. IL-27. Recent studies have shown that IL-27 inhibits Th17 cell differentiation $[52,95,96]$. This also affected the Th2 response in mouse models of allergic conjunctivitis. Chen et al.'s research results [78] confirmed that the inhibition and depletion of the IL-27 signal intensified the dominant role of Th2, which was realized through reducing IL-27's antagonism of GATA3 expression [97]. They also confirmed that enhancing Th17 response by increasing $\mathrm{ROR} \gamma \mathrm{t}$ exacerbated allergic inflammation [78]. At the same time, Th1 response was inhibited by suppression and consumption of the IL-27 signal, and the Th2 response advantage was further expanded. Their experiments also confirmed the promotion effect of Th17 on TH2 response.

3.4.2. OPN. OPN expression is enhanced in Th2 diseases (nasal polyps and allergic rhinitis) in the Chinese population, suggesting that OPN may enhance Th2 response $[98,99]$. Our study also provides possible evidence that OPN is involved in the Th17 response in AC. Several studies have investigated the role of OPN in promoting chemotactic inflammatory cells such as eosinophils and mast cells $[100,101]$. The correlation between OPN and disease severity and high OPN expression during allergy season suggest that OPN can be used as a possible biomarker for the differential diagnosis of other diseases, monitoring disease activity or response to treatment [101].

\section{Treatment and Management}

\subsection{Where Are We Now?}

4.1.1. Diagnosis. Diagnosis is based on allergic conjunctivitis clinical symptoms and conjunctival examination, but there are some laboratory tests that can usefully support this diagnosis [102, 103]. For example, skin tests for specific allergens can be performed by scratch tests or intradermal injections of allergens [104]. Some scholars have suggested skin prick tests should be included in the diagnostic work of AC patients for allergen immunotherapy [105]. These investigations should be able to find sensitivity to allergens including dust mites, animal dander, atmospheric mold, and seasonal pollen from grasses, trees, or weeds. Other scholars have suggested routine testing of food sensitivity in children, although food allergens are still controversial with regard to eye allergies [106]. Meanwhile, scraping the conjunctival surface to find eosinophils is a useful diagnostic method. The specific method is as follows: use the instrument to gently scrape several times on the inner surface of the conjunctiva. It is then stained with reagents. Check the slide for eosinophil granules or eosinophils. However, due to the presence of eosinophils in the conjunctiva typically deep, the upper layer may not be detected or not be eosinophils. Even the presence of only one eosinophil or eosinophil granule is 


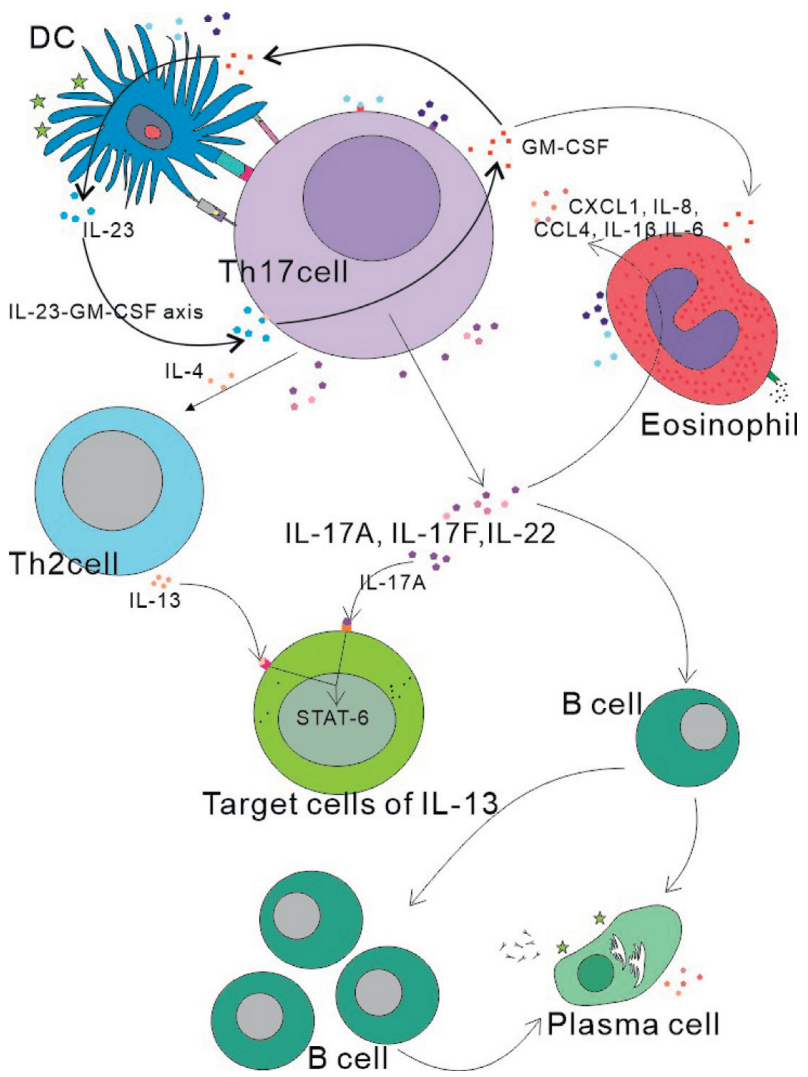

FIGURE 3: 1. The immune response is maintained by the IL-23-GMCSF axis. 2. IL-17A and IL-17F can promote the production of eosinophils CXCL1, IL-8, and CCL4, as well as IL-1 $\beta$ and IL-6. 3. IL-17A is involved in the pathophysiology of allergies by increasing the ability of IL-13 to activate signaling pathways such as intracellular STAT-6. IL-17A protein expression synergizes with IL-13. 4. Th17 cells have been shown to help B cell differentiation and to play a key role in the formation of ectopic lymphoid follicles in the target organ.

important evidence for the diagnosis of allergic conjunctivitis, and the diagnosis of allergy should not be ruled out without eosinophils [28]. Vitro testing of IgE antibodies and specific allergens are widely used [27]. Some scholars claim that the results of $\operatorname{IgE}$ of tears and $\operatorname{IgE}$ of serum are sometimes inconsistent, so the IgE positive rate of tears may be more meaningful for local allergic conjunctivitis [107].

4.1.2. Treatment and Management. Common treatments include eye drops containing antihistamine drugs, mast cell stabilizers, nonsteroidal drugs, and corticosteroids. Standard treatments are separate local antihistamine drug use or the use of local mast cell stabilizers alone or topical dual antihistamine-mast cell stabilizing agents [108-110]. They can effectively reduce the symptoms and signs of AC. Steroids can be given in the short term in the presence of severe symptoms and lack of response to other treatments [110]. Immunomodulators can effectively inhibit the activation of $\mathrm{T}$ cells and can treat severe allergic eye diseases. Immunomodulators alter the normal immune pathway and provide an alternative to steroids for allergic conjunctival disease
[111]. Meanwhile, allergen immunotherapy is both safe and effective treatment [103]. In addition, the current major advances in treatment are immunotherapy, including classic subcutaneous and sublingual immunotherapy and novel subcutaneous and intralymphatic immunotherapy drug delivery systems, as well as edible rice vaccines $[109,112]$.

4.2. Future Diagnosis and Treatment Options. Th17 cells have been recently implicated in steroid resistance mechanisms. Recent evidence suggests that Th17 cells can have a dual response to glucocorticoids. According to immunopathology, they can be very sensitive to glucocorticoids or resistant to glucocorticoids, and this feature behavior has been stated in Banuelos et al.'s extensive overview [113]. Therefore, the tool-targeted IL-17 pathway may be more valuable for patients with hormone-resistant allergic conjunctivitis. For instance, common motif biomolecule of IL-17A and IL-17F is currently in clinical development, including nanobodies ALX-0761 and $\mathrm{mAb}$ bimekizumab [87, 114]. Moreover, IL-17A blocking antibodies sukinumab and ixekizumab have been recently used to treat psoriasis and ankylosing spondylitis. $[115,116]$. Similarly, anti-IL-23 monoclonal therapy may be effective in eliminating the Th17 cell-eosinophil axis [51]. A simpler treatment may be used to inhibit eosinophil peroxidase with antioxidants such as vitamin E, limiting the main factors that cause the damage observed in these studies [51, 117]. Gallic acid treatment downregulated the expression of ROR $\gamma \mathrm{t}$ and IL-17 [71]. However, their effectiveness and safety in the application of allergic conjunctivitis are yet to be confirmed. However, their treatment of hormone-insensitive AC patients can provide more ideas.

\section{Abbreviations}

AC: Allergic conjunctivitis

SAC: Seasonal allergic conjunctivitis

PAC: Perennial allergic conjunctivitis

AKC: Atopic keratoconjunctivitis

VKC: Vernal keratoconjunctivitis

GPC: Giant papillary conjunctivitis

Th: T-helper

IL: Interleukin

DC: Dendritic cells

APC: Antigen-presenting cells

MC: $\quad$ Mast cells

ROR $\gamma \mathrm{t}$ : Retinoid-related orphan receptor $\gamma \mathrm{t}$

GM- Granulocyte-macrophage colony-stimulating

CSF: factor

TGF- $\beta$ : Transforming growth factor $\beta$

STAT3: Signal transduction and activation of transcription factor 3

STAT6: Signal transduction and activation of transcription factor 6 .

\section{Conflicts of Interest}

The authors declare that they have no conflicts of interest. 


\section{Authors' Contributions}

XTM was the main writer of the paper, YYS assisted in reviewing the literature, $\mathrm{HZ}$ assisted in revising the paper, and HYZ reviewed and revised the paper. All the authors read and approved the paper.

\section{Acknowledgments}

The authors thank Meng-Yu Shi for proofreading and editing of this manuscript. This work was supported by Provincial Office Bureau Project (SCZSY201730 and 3D518V563429); all costs related to study design, study performance, and analysis and interpretation of data as well as manuscript writing were supported by the fund.

\section{References}

[1] A. Leonardi, A. Castegnaro, A. L. G. Valerio, and D. Lazzarini, "Epidemiology of allergic conjunctivitis," Current Opinion in Allergy and Clinical Immunology, vol. 15, no. 5, pp. 482-488, 2015.

[2] M. S. Blaiss, E. Hammerby, S. Robinson, T. Kennedy-Martin, and S. Buchs, "The burden of allergic rhinitis and allergic rhinoconjunctivitis on adolescents," Annals of Allergy, Asthma \& Immunology, vol. 121, no. 1, pp. 43.e3-52.e3, 2018.

[3] E. Morikawa, M. Sasaki, K. Yoshida, Y. Adachi, H. Odajima, and A. Akasawa, "Nationwide survey of the prevalence of wheeze, rhino-conjunctivitis, and eczema among Japanese children in 2015," Allergology International, vol. 69, no. 1, pp. 98-103, 2020.

[4] A. V. Das, P. R. Donthineni, S. Prashanti, and S. Basu, "Allergic eye disease in children and adolescents seeking eye care in India: electronic medical records driven big data analytics report II," The Ocular Surface, vol. 17, no. 4, pp. 683-689, 2019.

[5] E. O. Meltzer, J. R. Farrar, and C. Sennett, "Findings from an online survey assessing the burden and management of seasonal allergic rhino conjunctivitis in US patients," The Journal of Allergy and Clinical Immunology: In Practice, vol. 5, no. 3, pp. 779.e6-789.e6, 2017.

[6] R. Shokouhi Shoormasti, Z. Pourpak, M. R. Fazlollahi et al., "The prevalence of allergic rhinitis, allergic conjunctivitis," Atopic Dermatitis and Asthma among Adults of Tehran, vol. 47, no. 11, pp. 1749-1755, 2018.

[7] R. Pawankar, "Allergic diseases and asthma: a global public health concern and a call to action," World Allergy Organization Journal, vol. 7, no. 1, p. 12, 2014.

[8] S. J. Ono and M. B. Abelson, "Allergic conjunctivitis: update on pathophysiology and prospects for future treatment," Journal of Allergy and Clinical Immunology, vol. 115, no. 1, pp. 118-122, 2005.

[9] K. Singh, S. Axelrod, and L. Bielory, "The epidemiology of ocular and nasal allergy in the United States, 1988-1994," Journal of Allergy and Clinical Immunology, vol. 126, no. 4, pp. 778.e6-783.e6, 2010.

[10] P. S. Bilkhu, J. S. Wolffsohn, and S. A. Naroo, "A review of non-pharmacological and pharmacological management of seasonal and perennial allergic conjunctivitis," Contact Lens and Anterior Eye, vol. 35, no. 1, pp. 9-16, 2012.

[11] Y.-J. Tang, H.-H. Chang, C.-Y. Chiang et al., "A murine model of acute allergic conjunctivitis induced by continuous exposure to particulate matter 2.5," Investigative Opthalmology \& Visual Science, vol. 60, no. 6, pp. 2118-2126, 2019.

[12] R. Pawankar, "Climate change, air pollution, and biodiversity in Asia Pacific: impact on allergic diseases," Asia Pacific Allergy, vol. 9, no. 2, p. e11, 2019.

[13] E. A. Mitchell, R. Beasley, U. Keil, S. Montefort, and J. Odhiambo, "The association between tobacco and the risk of asthma, rhino conjunctivitis and eczema in children and adolescents: analyses from phase three of the ISAAC programme," Thorax, vol. 67, no. 11, pp. 941-949, 2012.

[14] G. D’Amato, C. E. Baena-Cagnani, L. Cecchi et al., "Climate change, air pollution and extreme events leading to increasing prevalence of allergic respiratory diseases," Multidisciplinary Respiratory Medicine, vol. 8, no. 1, p. 12, 2013.

[15] M. S. Blaiss, M. S. Dykewicz, D. P. Skoner et al., "Diagnosis and treatment of nasal and ocular allergies: the allergies, immunotherapy, and rhino conjunctivitis (AIRS) surveys," Annals of Allergy, Asthma \& Immunology, vol. 112, no. 4, pp. 322-328, 2014.

[16] L. Bielory, D. P. Skoner, M. S. Blaiss et al., "Ocular and nasal allergy symptom burden in America: the allergies, immunotherapy, and rhino conjunctivitis (AIRS) surveys," Allergy and Asthma Proceedings, vol. 35, no. 3, pp. 211-218, 2014.

[17] F. Allen-Ramey, G. Ferrante, G. Cuttitta et al., "The burden of rhinitis and rhino conjunctivitis in adolescents," Allergy, Asthma \& Immunology Research, vol. 7, no. 1, pp. 44-50, 2015.

[18] K. ÅMed, A. Luukkainen, J. Pekkanen et al., "Self-reported allergic rhinitis and/or allergic conjunctivitis associate with IL13 rs20541 polymorphism in finnish adult asthma patients," International Archives of Allergy and Immunology, vol. 172, no. 2, pp. 123-128, 2017.

[19] S. Gabet, F. Ranciere, J. Just et al., "Asthma and allergic rhinitis risk depends on house dust mite specific IgE levels in Paris birth cohort children," World Allergy Organization Journal, vol. 12, no. 9, Article ID 100057, 2019

[20] A. Leonardi, E. Bogacka, J. L. Fauquert et al., "Ocular allergy: recognizing and diagnosing hypersensitivity disorders of the ocular surface," Allergy, vol. 67, no. 11, pp. 1327-1337, 2012.

[21] M. H. Friedlaender, "Ocular allergy," Current Opinion in Allergy and Clinical Immunology, vol. 11, no. 5, pp. 477-482, 2011.

[22] M. Kuruvilla, J. Kalangara, and F. E. Lee, "Neuropathic pain and itch mechanisms underlying allergic conjunctivitis," Journal of Investigational Allergology and Clinical Immunology, vol. 29, no. 5, pp. 349-356, 2019.

[23] J. L. Brozek, J. Bousquet, C. E. Baena-Cagnani et al., "Allergic rhinitis and its impact on asthma (ARIA) guidelines: 2010 revision," Journal of Allergy and Clinical Immunology, vol. 126 , no. 3, pp. 466-476, 2010.

[24] A. A. Azari and N. P. Barney, "Conjunctivitis: a systematic review of diagnosis and treatment," JAMA, vol. 310, no. 16, pp. 1721-1729, 2013.

[25] N. Alsulaiman and A. H. Alsuhaibani, "Bicanalicular silicone intubation for the management of punctal stenosis and obstruction in patients with allergic conjunctivitis," Ophthalmic Plastic and Reconstructive Surgery, vol. 35, no. 5, pp. 451-455, 2019.

[26] L. Chen, L. Pi, J. Fang, X. Chen, N. Ke, and Q. Liu, "High incidence of dry eye in young children with allergic conjunctivitis in Southwest China," Acta Ophthalmologica, vol. 94, no. 8, pp. e727-e730, 2016.

[27] M. La Rosa, E. Lionetti, M. Reibaldi et al., "Allergic conjunctivitis: a comprehensive review of the literature," Italian Journal of Pediatrics, vol. 39, no. 1, p. 18, 2013. 
[28] L. Bielory and M. H. Friedlaender, "Allergic conjunctivitis," Immunology and Allergy Clinics of North America, vol. 28, no. 1, pp. 43-58, 2008.

[29] L. Bielory, "Allergic conjunctivitis and the impact of allergic rhinitis," Current Allergy and Asthma Reports, vol. 10, no. 2, pp. 122-134, 2010.

[30] J. Palmares, L. Delgado, M. Cidade, M. J. Quadrado, H. P. Filipe, and G. Season Study, "Allergic conjunctivitis: a national cross-sectional study of clinical characteristics and quality of life," European Journal of Ophthalmology, vol. 20, no. 2, pp. 257-264, 2010.

[31] D. Bremond-Gignac, J. Donadieu, A. Leonardi et al., "Prevalence of vernal kerato conjunctivitis: a rare disease?" British Journal of Ophthalmology, vol. 92, no. 8, pp. 10971102, 2008.

[32] M. T. Irkec and B. Bozkurt, "Molecular immunology of allergic conjunctivitis," Current Opinion in Allergy and Clinical Immunology, vol. 12, no. 5, pp. 534-539, 2012.

[33] K. W. Kim, H. R. Kim, B. M. Kim, M. L. Cho, and S. H. Lee, "Th17 cytokines regulate osteoclastogenesis in rheumatoid arthritis," The American Journal of Pathology, vol. 185, no. 11, pp. 3011-3024, 2015.

[34] M. Sarra, F. Pallone, T. T. Macdonald, and G. Monteleone, "IL-23/IL-17 axis in IBD," Inflammatory Bowel Diseases, vol. 16, no. 10, pp. 1808-1813, 2010.

[35] D. Elieh Ali Komi, T. Rambasek, and L. Bielory, "Clinical implications of mast cell involvement in allergic conjunctivitis," Allergy, vol. 73, no. 3, pp. 528-539, 2018.

[36] T. R. Mosmann and R. L. Coffman, "TH1 and TH2 cells: different patterns of lymphokine secretion lead to different functional properties," Annual Review of Immunology, vol. 7, pp. 145-173, 1989.

[37] L. Bielory, "Ocular allergy and dry eye syndrome," Current Opinion in Allergy and Clinical Immunology, vol. 4, no. 5, pp. 421-424, 2004.

[38] D. E. A. Komi, T. Rambasek, and S. Wöhrl, "Mastocytosis: from a molecular point of view," Clinical Reviews in Allergy \& Immunology, vol. 54, no. 3, pp. 397-411, 2018.

[39] W. Ellmeier, A. Abramova, and A. Schebesta, "Tec family kinases: regulation of FceRI-mediated mast-cell activation," FEBS Journal, vol. 278, no. 12, pp. 1990-2000, 2011.

[40] P. Draber, I. Halova, F. Levi-Schaffer, and L. Draberova, "Transmembrane adaptor proteins in the high-affinity IgE receptor signaling," Frontiers in Immunology, vol. 2, p. 95, 2012.

[41] M. Ohbayashi, B. Manzouri, K. Morohoshi, K. Fukuda, and S. J. Ono, "The role of histamine in ocular allergy," in Advances in Experimental Medicine and Biology, vol. 709, pp. 43-52, Springer, Berlin, Germany, 2010.

[42] J.-F Huang and R. L. Thurmond, "The new biology of histamine receptors," Current Allergy and Asthma Reports, vol. 8, no. 1, pp. 21-27, 2008.

[43] A. Leonardi, A. Di Stefano, C. Vicari, L. Motterle, and P. Brun, "Histamine $\mathrm{H} 4$ receptors in normal conjunctiva and in vernal kerato conjunctivitis," Allergy, vol. 66, no. 10, pp. 1360-1366, 2011.

[44] J. L. Fauquert, "Diagnosing and managing allergic conjunctivitis in childhood: the allergist's perspective," Pediatric Allergy and Immunology, vol. 30, no. 4, pp. 405-414, 2019.

[45] O. Sakai, Y. Tamada, T. R. Shearer, and M. Azuma, "Involvement of $\mathrm{NF} \kappa \mathrm{B}$ in the production of chemokines by rat and human conjunctival cells cultured under allergenic conditions," Current Eye Research, vol. 38, no. 8, pp. 825834, 2013.
[46] L. Vocca, C. Di Sano, C. G. Uasuf et al., "IL-33/ST2 axis controls Th2/IL-31 and Th17 immune response in allergic airway diseases," Immunobiology, vol. 220, no. 8, pp. $954-$ 963, 2015.

[47] E. Bettelli, T. Korn, and V. K. Kuchroo, "Th17: the third member of the effector T cell trilogy," Current Opinion in Immunology, vol. 19, no. 6, pp. 652-657, 2007.

[48] D. D. Patel and V. K. Kuchroo, "Th17 cell pathway in human immunity: lessons from genetics and therapeutic interventions," Immunity, vol. 43, no. 6, pp. 1040-1051, 2015.

[49] Z. Chen, A. Laurence, and J. J. O'Shea, "Signal transduction pathways and transcriptional regulation in the control of Th17 differentiation," Seminars in Immunology, vol. 19, no. 6 , pp. 400-408, 2007.

[50] J. F. Alcorn, C. R. Crowe, and J. K. Kolls, "TH17 cells in asthma and COPD," Annual Review of Physiology, vol. 72, no. 1, pp. 495-516, 2010.

[51] S. Keely and P. S. Foster, "Stop press: eosinophils drafted to join the Th17 team," Immunity, vol. 43, no. 1, pp. 7-9, 2015.

[52] C. Diveu, M. J. McGeachy, K. Boniface et al., "IL-27 blocks RORc expression to inhibit lineage commitment of Th17 cells," The Journal of Immunology, vol. 182, no. 9, pp. 5748-5756, 2009.

[53] S. L. Gaffen, "Structure and signalling in the IL-17 receptor family," Nature Reviews Immunology, vol. 9, no. 8, pp. 556-567, 2009.

[54] Z. W. Gu, Y. X. Wang, and Z. W. Cao, "Neutralization of interleukin-17 suppresses allergic rhinitis symptoms by downregulating Th2 and Th17 responses and upregulating the treg response," Oncotarget, vol. 8, no. 14, pp. 22361-22369, 2017.

[55] T. T. Bui, C. H. Piao, C. H. Song, H. S. Shin, D.-H. Shon, and O. K. Chai, "Piper nigrum extract ameliorated allergic inflammation through inhibiting Th2/Th17 responses and mast cells activation," Cellular Immunology, vol. 322, pp. 64-73, 2017.

[56] M. E. Poynter, "Do insights from mice imply that combined Th2 and Th17 therapies would benefit select severe asthma patients?" Annals of Translational Medicine, vol. 4, no. 24, p. 505, 2016.

[57] H. Kebir, K. Kreymborg, I. Ifergan et al., "Human TH17 lymphocytes promote blood-brain barrier disruption and central nervous system inflammation," Nature Medicine, vol. 13, no. 10, pp. 1173-1175, 2007.

[58] D. Yen, J. Cheung, H. Scheerens et al., "IL-23 is essential for T cell-mediated colitis and promotes inflammation via IL-17 and IL-6," Journal of Clinical Investigation, vol. 116, no. 5, pp. 1310-1316, 2006.

[59] P. R. Taylor, R. Roy, S. M. Leal et al., "Activation of neutrophils by autocrine IL-17A-IL-17RC interactions during fungal infection is regulated by IL-6, IL-23, ROR $\gamma \mathrm{t}$ and dectin-2," Nature Immunology, vol. 15, no. 2, pp. 143-151, 2014.

[60] M. J. McGeachy, D. J. Cua, and S. L. Gaffen, "The IL-17 family of cytokines in health and disease," Immunity, vol. 50, no. 4, pp. 892-906, 2019.

[61] F. Maione, "Commentary: IL-17 in chronic inflammation: from discovery to targeting," Frontiers in Pharmacology, vol. 7, p. 250, 2016.

[62] D. C. Newcomb and R. S. Peebles Jr., "Th17-mediated inflammation in asthma," Current Opinion in Immunology, vol. 25, no. 6, pp. 755-760, 2013.

[63] H. Wakashin, K. Hirose, Y. Maezawa et al., "IL-23 and Th17 cells enhance Th2-cell-mediated eosinophilic airway 
inflammation in mice," American Journal of Respiratory and Critical Care Medicine, vol. 178, no. 10, pp. 1023-1032, 2008.

[64] M. W. Kinyanjui, J. Shan, E. M. Nakada, S. T. Qureshi, and E. D. Fixman, "Dose-dependent effects of IL-17 on IL-13induced airway inflammatory responses and airway hyperresponsiveness," The Journal of Immunology, vol. 190, no. 8, pp. 3859-3868, 2013.

[65] Y. H. Wang, K. S. Voo, B. Liu et al., "A novel subset of $\mathrm{CD} 4(+) \mathrm{T}(\mathrm{H}) 2$ memory/effector cells that produce inflammatory IL-17 cytokine and promote the exacerbation of chronic allergic asthma," Journal of Experimental Medicine, vol. 207, no. 11, pp. 2479-2491, 2010.

[66] Y. Chang, L. Al-Alwan, P. A. Risse et al., "Th17-associated cytokines promote human airway smooth muscle cell proliferation," The FASEB Journal, vol. 26, no. 12, pp. 5152-5160, 2012.

[67] P. F. Cheung, C. K. Wong, and C. W. Lam, "Molecular mechanisms of cytokine and chemokine release from eosinophils activated by IL-17A, IL-17F, and IL-23: implication for Th17 lymphocytes-mediated allergic inflammation," The Journal of Immunology, vol. 180, no. 8, pp. 5625-5635, 2008.

[68] S. Nakae, Y. Komiyama, A. Nambu et al., "Antigen-specific $\mathrm{T}$ cell sensitization is impaired in IL-17-deficient mice, causing suppression of allergic cellular and humoral responses," Immunity, vol. 17, no. 3, pp. 375-387, 2002.

[69] C. Song, L. Luo, Z. Lei et al., "IL-17-producing alveolar macrophages mediate allergic lung inflammation related to asthma," The Journal of Immunology, vol. 181, no. 9, pp. 6117-6124, 2008.

[70] S. Lajoie, I. P. Lewkowich, Y. Suzuki et al., "Complementmediated regulation of the IL-17A axis is a central genetic determinant of the severity of experimental allergic asthma," Nature Immunology, vol. 11, no. 10, pp. 928-935, 2010.

[71] Y. Fan, C. H. Piao, E. Hyeon et al., "Gallic acid alleviates nasal inflammation via activation of Th1 and inhibition of Th2 and Th17 in a mouse model of allergic rhinitis," International Immunopharmacology, vol. 70, pp. 512-519, 2019.

[72] A. R. Castaneda, C. F. A. Vogel, K. J. Bein, H. K. Hughes, S. Smiley-Jewell, and K. E. Pinkerton, "Ambient particulate matter enhances the pulmonary allergic immune response to house dust mite in a BALB/c mouse model by augmenting Th2- and Th17-immune responses," Physiological Reports, vol. 6, no. 18, Article ID e13827, 2018.

[73] T. Yoshimura, K. H. Sonoda, N. Ohguro et al., "Involvement of Th17 cells and the effect of anti-IL-6 therapy in autoimmune uveitis," Rheumatology (Oxford), vol. 48, no. 4, pp. 347-354, 2009.

[74] C. S. De Paiva, S. Chotikavanich, S. B. Pangelinan et al., "IL17 disrupts corneal barrier following desiccating stress," Mucosal Immunology, vol. 2, no. 3, pp. 243-253, 2009.

[75] A. Amadi-Obi, C. R. Yu, X. Liu et al., "TH17 cells contribute to uveitis and scleritis and are expanded by IL-2 and inhibited by IL-27/STAT1," Nature Medicine, vol. 13, no. 6, pp. 711-718, 2007.

[76] M. H. Kang, M. K. Kim, H. J. Lee, H. I. Lee, W. R. Wee, and J. K. Lee, "Interleukin-17 in various ocular surface inflammatory diseases," Journal of Korean Medical Science, vol. 26, no. 7, pp. 938-944, 2011.

[77] A.-W. Qiu, Q.-H. Liu, and J.-L. Wang, "Blocking IL-17A alleviates diabetic retinopathy in rodents," Cellular Physiology and Biochemistry, vol. 41, no. 3, pp. 960-972, 2017.

[78] X. Chen, R. Deng, W. Chi et al., "IL-27 signaling deficiency develops Th17-enhanced Th2-dominant inflammation in murine allergic conjunctivitis model," Allergy, vol. 74, no. 5, pp. 910-921, 2019.

[79] H. Vroman, B. van den Blink, and M. Kool, "Mode of dendritic cell activation: the decisive hand in Th2/Th17 cell differentiation. Implications in asthma severity?" Immunobiology, vol. 220, no. 2, pp. 254-261, 2015.

[80] H. Vroman, I. M. Bergen, J. A. C. van Hulst et al., "TNF$\alpha$-induced protein 3 levels in lung dendritic cells instruct T2 or T17 cell differentiation in eosinophilic or neutrophilic asthma," Journal of Allergy and Clinical Immunology, vol. 141, no. 5, pp. 1620.e12-1633.e12, 2018.

[81] M. Kudo, A. C. Melton, C. Chen et al., "IL-17A produced by alphabeta T cells drives airway hyper-responsiveness in mice and enhances mouse and human airway smooth muscle contraction," Nature Medecine, vol. 18, no. 4, pp. 547-554, 2012.

[82] G. Huang, Y. Wang, and H. Chi, "Regulation of TH17 cell differentiation by innate immune signals," Cellular and Molecular Immunology, vol. 9, no. 4, pp. 287-295, 2012.

[83] W. Liu, S. Liu, M. Verma et al., "Mechanism of TH2/TH17predominant and neutrophilic TH2/TH17-low subtypes of asthma," Journal of Allergy and Clinical Immunology, vol. 139, no. 5, pp. 1548.e4-1558.e4, 2017.

[84] T. Korn, E. Bettelli, M. Oukka, and V. K. Kuchroo, "IL-17 and Th17 cells," Annual Review of Immunology, vol. 27, pp. 485-517, 2009.

[85] M. J. McGeachy, Y. Chen, C. M. Tato et al., "The interleukin 23 receptor is essential for the terminal differentiation of interleukin 17-producing effector T helper cells in vivo," Nature Immunology, vol. 10, no. 3, pp. 314-324, 2009.

[86] S. Makihara, M. Okano, T. Fujiwara et al., "Regulation and characterization of IL-17A expression in patients with chronic rhinosinusitis and its relationship with eosinophilic inflammation," Journal of Allergy and Clinical Immunology, vol. 126, no. 2, pp. 397.e11-400.e11, 2010.

[87] R. K. Ramakrishnan, S. Al Heialy, and Q. Hamid, "Role of IL17 in asthma pathogenesis and its implications for the clinic," Expert Review of Respiratory Medicine, vol. 13, no. 11, pp. 1057-1068, 2019.

[88] S. S. Candrian, D. Togbe, I. Couillin et al., "Interleukin-17 is a negative regulator of established allergic asthma," Journal of Experimental Medicine, vol. 203, no. 12, pp. 2715-2725, 2006.

[89] H.-C. Hsu, P. Yang, J. Wang et al., "Interleukin 17-producing $\mathrm{T}$ helper cells and interleukin 17 orchestrate autoreactive germinal center development in autoimmune BXD2 mice," Nature Immunology, vol. 9, no. 2, pp. 166-175, 2008.

[90] M. Mitsdoerffer, Y. Lee, A. Jager et al., "Proinflammatory T helper type 17 cells are effective B-cell helpers," Proceedings of the National Academy of Sciences, vol. 107, no. 32, pp. 14292-14297, 2010.

[91] T. Griseri, I. C. Arnold, C. Pearson et al., "Granulocyte macrophage colony-stimulating factor-activated eosinophils promote interleukin-23 driven chronic colitis," Immunity, vol. 43, no. 1, pp. 187-199, 2015.

[92] L. Monin and S. L. Gaffen, "Interleukin 17 family cytokines: signaling mechanisms, biological activities, and therapeutic implications," Cold Spring Harbor Perspectives in Biology, vol. 10, no. 4, 2018.

[93] M.-E Behi, B. Ciric, H. Dai et al., "The encephalitogenicity of $\mathrm{T}(\mathrm{H}) 17$ cells is dependent on IL-1- and IL-23-induced production of the cytokine GM-CSF," Nature Immunology, vol. 12, no. 6, pp. 568-575, 2011.

[94] K. Takahashi, K. Hirose, S. Kawashima et al., "IL-22 attenuates IL-25 production by lung epithelial cells and inhibits 
antigen-induced eosinophilic airway inflammation," Journal of Allergy and Clinical Immunology, vol. 128, no. 5, pp. 1067.e6-1076.e6, 2011.

[95] C. Pot, L. Apetoh, A. Awasthi, and V. K. Kuchroo, "Induction of regulatory $\mathrm{Tr} 1$ cells and inhibition of $\mathrm{T}(\mathrm{H}) 17$ cells by IL-27," Seminars in Immunology, vol. 23, no. 6, pp. 438-445, 2011.

[96] C. Neufert, C. Becker, S. Wirtz et al., "IL-27 controls the development of inducible regulatory T cells and Th17 cells via differential effects on STAT1," European Journal of Immunology, vol. 37, no. 7, pp. 1809-1816, 2007.

[97] T. Yoshimoto, T. Yoshimoto, K. Yasuda, J. Mizuguchi, and K. Nakanishi, "IL-27 suppresses Th2 cell development and Th2 cytokines production from polarized Th2 cells: a novel therapeutic way for Th2-mediated allergic inflammation," Journal of Immunology, vol. 179, no. 7, pp. 4415-4423, 2007.

[98] W. Liu, W. Xia, Y. Fan et al., "Elevated serum osteopontin level is associated with blood eosinophilia and asthma comorbidity in patients with allergic rhinitis," Journal of Allergy and Clinical Immunology, vol. 130, no. 6, pp. 1416.e6-1418.e6, 2012.

[99] W.-L. Liu, H. Zhang, Y. Zheng et al., "Expression and regulation of osteopontin in chronic rhinosinusitis with nasal polyps," Clinical and Experimental Allergy, vol. 45, no. 2, pp. 414-422, 2015.

[100] Y. Asada, M. Okano, W. Ishida et al., "Periostin deletion suppresses late-phase response in mouse experimental allergic conjunctivitis," Allergology International, vol. 68, no. 2, pp. 233-239, 2019.

[101] A. Yan, G. Luo, Z. Zhou, W. Hang, and D. Qin, "Tear osteopontin level and its relationship with local Th1/Th2/ Th17/Treg cytokines in children with allergic conjunctivitis," Allergologia et Immunopathologia, vol. 46, no. 2, pp. 144-148, 2018.

[102] A. Wong, S. Barg, and A. Leung, "Seasonal and perennial allergic conjunctivitis," Recent Patents on Inflammation \& Allergy Drug Discovery, vol. 8, no. 2, pp. 139-153, 2014.

[103] M. Castillo, N. W. Scott, M. Z. Mustafa, M. S. Mustafa, and A. A. Blanco, "Topical antihistamines and mast cell stabilisers for treating seasonal and perennial allergic conjunctivitis," Cochrane Database of Systematic Reviews, no. 6, Article ID CD009566, 2015.

[104] P. A. Miranda-Machado and B. De la Cruz-Hoyos Sanchez, "Skin reactivity in allergic conjunctivitis," Revista Alergia México, vol. 65, no. 3, pp. 208-216, 2018.

[105] K. M. Sayed, A. G. Kamel, and A. H. Ali, "One-year evaluation of clinical and immunological efficacy and safety of sublingual versus subcutaneous allergen immunotherapy in allergic conjunctivitis," Graefe's Archive for Clinical and Experimental Ophthalmology, vol. 257, no. 9, pp. 1989-1996, 2019.

[106] H. Lindvik, K. C. Lødrup Carlsen, P. Mowinckel, J. Navaratnam, M. P. Borres, and K.-H. Carlsen, "Conjunctival provocation test in diagnosis of peanut allergy in children," Clinical and Experimental Allergy, vol. 47, no. 6, pp. 785-794, 2017.

[107] Y. Yamana, K. Fukuda, R. Ko, and E. Uchio, "Local allergic conjunctivitis: a phenotype of allergic conjunctivitis," International Ophthalmology, vol. 39, no. 11, pp. 2539-2544, 2019.

[108] A. Leonardi, S. Doan, J. L. Fauquert et al., "Diagnostic tools in ocular allergy," Allergy, vol. 72, no. 10, pp. 1485-1498, 2017.
[109] L. Bielory and D. Schoenberg, "Ocular allergy," Current Opinion in Allergy and Clinical Immunology, vol. 19, no. 5, pp. 495-502, 2019.

[110] A. Leonardi, D. Silva, D. P. Formigo et al., "Management of ocular allergy," Allergy, vol. 74, no. 9, pp. 1611-1630, 2019.

[111] M. B. Abelson, S. Shetty, M. Korchak, S. I. Butrus, and L. M. Smith, "Advances in pharmacotherapy for allergic conjunctivitis," Expert Opinion on Pharmacotherapy, vol. 16, no. 8, pp. 1219-1231, 2015.

[112] K. Fukuda, W. Ishida, Y. Harada et al., "Efficacy of oral immunotherapy with a rice-based edible vaccine containing hypoallergenic Japanese cedar pollen allergens for treatment of established allergic conjunctivitis in mice," Allergology International, vol. 67, no. 1, pp. 119-123, 2018.

[113] J. Banuelos, Y. Cao, S. C. Shin, and N. Z. Lu, "Immunopathology alters Th17 cell glucocorticoid sensitivity," Allergy, vol. 72, no. 3, pp. 331-341, 2017.

[114] M. Silacci, W. Lembke, R. Woods et al., "Discovery and characterization of COVA322, a clinical-stage bispecific TNF/IL-17A inhibitor for the treatment of inflammatory diseases," $m A b s$, vol. 8, no. 1, pp. 141-149, 2016.

[115] K. A. Papp, C. L. Leonardi, A. Blauvelt et al., "Ixekizumab treatment for psoriasis: integrated efficacy analysis of three double-blinded, controlled studies (UNCOVER-1, UNCOVER-2, UNCOVER-3)," British Journal of Dermatology, vol. 178, no. 3, pp. 674-681, 2018.

[116] C.-Y. Wu, H.-Y. Chiu, and T.-F. Tsai, "The seroconversion rate of QuantiFERON-TB Gold In-Tube test in psoriatic patients receiving secukinumab and ixekizumab, the antiinterleukin-17A monoclonal antibodies," PLoS One, vol. 14, no. 12, Article ID e0225112, 2019.

[117] H. Cui, J. Huang, M. Lu et al., "Antagonistic effect of vitamin $\mathrm{E}$ on nAlO-induced exacerbation of Th2 and Th17-mediated allergic asthma via oxidative stress," Environmental Pollution, vol. 252, pp. 1519-1531, 2019. 